Fixed Point Theory, 19(2018), No. 1, 235-248

DOI 10.24193/fpt-ro.2018.1.19

http://www.math.ubbcluj.ro/ nodeacj/sfptcj.html

\title{
ON BANACH CONTRACTION PRINCIPLES IN FUZZY METRIC SPACES
}

\author{
VALENTÍN GREGORI*, JUAN-JOSÉ MIÑANA** AND ALMANZOR SAPENA* \\ *Instituto Universitario de Matemática Pura y Aplicada \\ Campus de Gandia, Universitat Politècnica de València, Spain \\ E-mail: vgregori@mat.upv.es
}

** Departament de Ciències Matemátiques i Informática, Universitat de les Illes Balears, Spain

Abstract. In this paper we discuss the concept of Cauchy sequence due to Grabiec, that we call $G$-Cauchy, in the context of fuzzy metric spaces. It leads to introduce and study a concept of weak $G$-completeness in fuzzy and classical context. Then, we generalize the celebrated Grabiec's fuzzy Banach Contraction Principle. Also, we extend the Mihet's fixed point theorem given for weak $B$-contractive mappings.

Key Words and Phrases: Fixed point theorem, fuzzy metric space, $G$-Cauchy sequence. 2010 Mathematics Subject Classification: 54A40, 54D35, 54E50.

Acknowledgements. Valentín Gregori acknowledges the support of Ministry of Economy and Competitiveness of Spain under grant MTM MTM2015-64373-P. Almanzor Sapena acknowledges the support of Ministry of Economy and Competitiveness of Spain under grant TEC2013-45492-R.

\section{REFERENCES}

[1] A. George, P. Veeramani, On some results in fuzzy metric spaces, Fuzzy Sets and Systems, 64(1994), 395-399.

[2] M. Grabiec, Fixed points in fuzzy metric spaces, Fuzzy Sets and Systems, 27(1989), 385-389.

[3] V. Gregori, J.J. Miñana, S. Morillas, Some questions in fuzzy metric spaces, Fuzzy Sets and Systems, 204(2012), 71-85.

[4] V. Gregori, S. Morillas, A. Sapena, On a class of completable fuzzy metric spaces, Fuzzy Sets and Systems, 161(2010), 2193-2205.

[5] V. Gregori, S. Romaguera, Characterizing completable fuzzy metric spaces, Fuzzy Sets and Systems, 144(2004), 411-420.

[6] V. Gregori, A. Sapena, On fixed-point theorems in fuzzy metric spaces, Fuzzy Sets and Systems, 125(2002), 245-252.

[7] I. Kramosil, J. Michalek, Fuzzy metrics and statistical metric spaces, Kybernetika, 11(1975), 326-334.

[8] D. Mihet, A Banach contraction theorem in fuzzy metric spaces, Fuzzy Sets and Systems, 144(2004), 431-439.

[9] D. Mihet, Fuzzy $\varphi$-contractive mappings in non-Archimedean fuzzy metric spaces, Fuzzy Sets and Systems, 159(2008), 739-744. 
[10] P. Tirado, On compactness and G-completeness in fuzzy metric spaces, Iranian J. Fuzzy Systems, 9(4)(2012), 151-158.

[11] P. Tirado, Contraction mappings in fuzzy quasi-metric spaces and $[0,1]$-posets, Fixed Point Theory, 13(2012), 273-283.

[12] S. Sharma, Common fixed point theorems in fuzzy metric spaces, Fuzzy Sets and Systems, 127(2002), 345-352.

[13] P.V. Subrahmanyam, A common fixed point theorem in fuzzy metric spaces, Information Sciences, 83(1995), 109-112.

[14] V.M. Sehgal, A.T. Bharucha-Reid, Fixed points of contraction mappings on PM-spaces, Math. Systems Theory, 6(1972), 97-100.

[15] R. Vasuki, A common fixed point theorem in a fuzzy metric space, Fuzzy Sets and Systems, 97(1998), 395-397.

Received: July 31, 2015; Accepted: February 12, 2016. 
